\title{
THE EFFECT OF STRENGTH EXERCISE ON THICKNESS AND FUNCTION OF QUADRICEPS MUSCLE IN SPORTING AND NON-SPORTING 11-13 YEAR OLD CHILDREN
}

\author{
Lina Levickiené $\dot{e}^{1}$, Daiva Imbrasiené $\dot{2}^{2}$, Monika Pociené $\dot{e}^{3}$, Vanda Jakubaitiené $\dot{e}^{4}$
}

\begin{abstract}
:
BACKGROUND: Physical activity is the key factor in a child's development and strong health. This includes physical, mental and functional body states. In Lithuania, as in the whole world, the physical activity of children is decreasing and this affects their growth and maturation.

OBJECTIVE OF STUDY: To evaluate the effect of exercises on the thickness and function of the quadriceps thigh muscle of sporting and non-sporting children 11-13 years of age.

METHODS: The research was carried out at one of Kaunas basic schools. Two tests were performed for this purpose before and after the study. In the study, a dominant leg measuring test and the thickness, volume and strength measuring of the quadriceps thigh muscle was performed. The received data was processed using SPSS 17.0 and a mathematical calculator in Microsoft Office Excel. The study lasted 5 months and a leg muscle strengthening exercise program was performed for 30 minutes twice a week. The participants performed 30 exercises in total.

RESULTS: The study involved 36 participants, which were grouped in two groups of 18 participants. Assessing the results of a study between a dominant and non-dominant leg, we found that the results of all measurements in both groups were not significantly different $(p>0.05)$. By analyzing the results of sporting and non-sporting groups before as well as after the study and after calculation of Pearson correlation coefficients, a greater link between the measured parameters was determined in the sporting group.
\end{abstract}

CONCLUSION: The results showed that the studied parameters (thickness, force and volume of the quadriceps thigh muscle) statistically increased significantly after strength exercises.

UDC Classification: 615.8; DOI: http://dx.doi.org/10.12955/cbup.v6.1273

Keywords: thickness of quadriceps thigh muscle, muscle force, strengthening exercises.

\section{Introduction}

The research shows that majority of pupils in Lithuania are not sufficiently physically active. Lack of physical activity affects their growth and puberty. The researchers who studied children's physical activity noticed its significant reduction tendencies. It is stated that about 85.5 percent of schoolchildren in Lithuania are not physically active, of which the majority consists of girls (Radzevičienè et al., 2016).

Continually decreasing physical activity among children promotes various disorders in the body (obesity, changes in the heart and blood vessel system, muscular skeletal system disorders, psychosocial ailments, disorders of vision, etc.). Due to the decrease in physical activity, these muscles show states of atrophy except those that are mostly active every day, such as the quadriceps thigh muscle.

Sport is one of the few actions in children life where they can engage in intensive activities. According to the World Health Organization (WHO) health-strengthening physical activity for children and youth is a moderate intensity physical activity not less than 60 minutes daily. The recommended minimum load - two times a week -helps to increase and maintain muscle strength and tone (Regional Office for Europe of the WHO, 2017).

Strength training is an important component in sport and rehabilitation. Training muscle strength also strengthens bones, ligaments, tendons, fascia's and cartilages (Skurvydas, 2011).

\footnotetext{
${ }^{1}$ Klaipeda State University of Applied Sciences, Faculty of Health Sciences, Department of Physiotherapy and Beauty Therapy, Lithuania, 1.levickiene@kvk.lt

${ }^{2}$ Lithuanian Sports University, Faculty of Sport Biomedicine, Department of Applied biology and

Rehabilitation, Lithuania, daiva.imbrasiene@1su.lt

${ }^{3}$ Klaipeda State University of Applied Sciences, Faculty of Health Sciences, Department of Physiotherapy and Beauty Therapy, Lithuania, m.pociene@kvk.lt

${ }^{4}$ Klaipeda State University of Applied Sciences, Faculty of Health Sciences, Department of Physiotherapy and

Beauty Therapy, Lithuania, vanda.jakubaitiene@gmail.com
} 
General strength training is recommended during adolescence because optimal strength and muscle balance are critical for the quality of a growing skeleton. Muscle strength exercises improved muscle performance, increased motor performance, improved body composition and increased bone strength (Brody \& Hall, 2018).

It is commonly believed that maximal force and muscle cross section are strongly related. However, there are not so many new scientific articles analyzing the differences in muscle size and functions among sporting and non-sporting teenagers.

Therefore, the study's basic aim was to find out how muscle size and function is different between sporting and non-sporting school children and the influences that the strengthening exercises have on muscle cross section, force and volume. Before the performance of this research, the hypothesis was raised that strengthening exercises would have a positive effect on the increase of quadriceps thigh muscle strength, thickness and thigh volume.

Tasks: 1. To assess the thickness and strength of the quadriceps thigh muscle and the thigh volume of sporting and non-sporting children 11-13 years of age before and after application of strengthening exercises. 2. To compare the results of thickness and strength of quadriceps thigh muscle and the volume of thighs among sexes. 3. To assess the strength, thickness and thigh volume of the quadriceps thigh muscle of the dominant and non-dominant leg. 4. To assess the correlation between the thickness, strength and volume of the quadriceps thigh muscle.

\section{Materials and Methods}

Subjects

The study was conducted at one of Kaunas basic schools. Prior to the start of the research, the school director's permission and parental consent in writing were received. 36 school children from the sixth grade participated in total. They were divided in two groups: sporting and non-sporting school children after classes. The sporting group was composed of school children who attended various sports not less than 2 times per week. The groups consisted of 18 participants: 12 boys (66,7 \%) and 6 girls $(33,3 \%)$. The average age in the sporting group was $11.8 \pm 0.1$ years of age and non-sporting group $12.0 \pm 0.1$ years of age.

Data collection and analysis

For the implementation of the research two tests before and after study were performed for this purpose. The test of the dominant leg involving measurement of the thigh volume and the strength of quadriceps muscle was carried out. The received data was processed using SPSS 17.0 and a mathematical calculator in Microsoft Office Excel. The research lasted 5 months and was carried out 2 times a week for 30 minutes followed by a leg muscle strengthening exercise program. There were 30 exercises in total.

1. Ascertainment of dominant leg. The dominant leg was ascertained by the help of a ball. Children were asked to come up to the ball and kick it. The dominant leg was determined by 3 trials.

2. Measurement of thigh volume. The volume of both thighs was measured using a distance of 20 $\mathrm{cm}$ above the patella as a starting point. The measurement was performed with a centimeter strip with a $1 \mathrm{~cm}$ error.

3. Measurement of muscle force. The quadriceps thigh muscle force was measured by a manual Lafayette dynamometer. The resulting force was expressed in kilograms $(\mathrm{kg})$. During testing the static muscle strength, the position of manual dynamometer and the tested person was selected according to the requirements submitted by Reese (2012):

- The position of the tested person: sitting on the edge of the table, the thigh up to the harness lies on the table, and the joint of the knee is bending at the angle of $45^{\circ}$.

- The position of dynamometer: the front surface of the calf $10 \mathrm{~cm}$ higher from the middle line of the ankle.

- The command to the tested person: to keep the leg in the testing position and not allow for the tested person to move it (Reese, 2012).

During testing, the tested school children underwent one unregistered trial, followed by 3 registered ones from which the average was calculated. Each test lasted 5 minutes. When the largest magnitude of muscle strength is gained, a signal sounds after which the measurement is completed. There were 30 seconds breaks between the tests. 
4. Measurement of muscle thickness. The thickness of the quadriceps thigh muscle was measured by an ultrasound apparatus. Ultrasound skeletal muscle tests were performed using the TITAN ultrasound diagnostic system and using ultrasonic HST/10-5 MHz 25mm linear sensors. The tests were performed in a relaxed and lying position. The quadriceps thigh muscle thickness was measured at 5 points. The points were chosen after taking an imaginary line between the upper edge of the patella and the anterior superior iliac spine every $5 \mathrm{~cm}$ that is $5,10,15,20$, and $25 \mathrm{~cm}$ in height from the edge of the patella. For comparison of the tests, measurements were performed on the symmetric points of both legs. The thickness of the muscles was assessed using the centimetric scales, which were visible on the monitor screen.

\section{Results}

The ball kicking test showed that the dominant leg was the right one in all of 18 (100\%) participants of non-sporting group. In the sporting group 17 (94.4\%) participants had their right leg as the dominant one and $1(5.6 \%)$ participant had the dominant leg as the left leg.

Comparing the results of thigh volume between sporting and non-sporting groups before and after the test, the higher volume in both legs was in the non-sporting group, however there was no significant difference $(\mathrm{p}>0.05)$. The results of both groups were statistically significant for thigh volume increase both in the right leg (sporting $-0.8 \pm 1.2 \mathrm{~cm}$, non-sporting group $-0.8 \pm 1.2 \mathrm{~cm}$ ) and in the right leg (sporting group - $1 \pm 1.4 \mathrm{~cm}$, non-sporting group $-0.9 \pm 0.2 \mathrm{~cm}$ ) as shown in Figure 1.

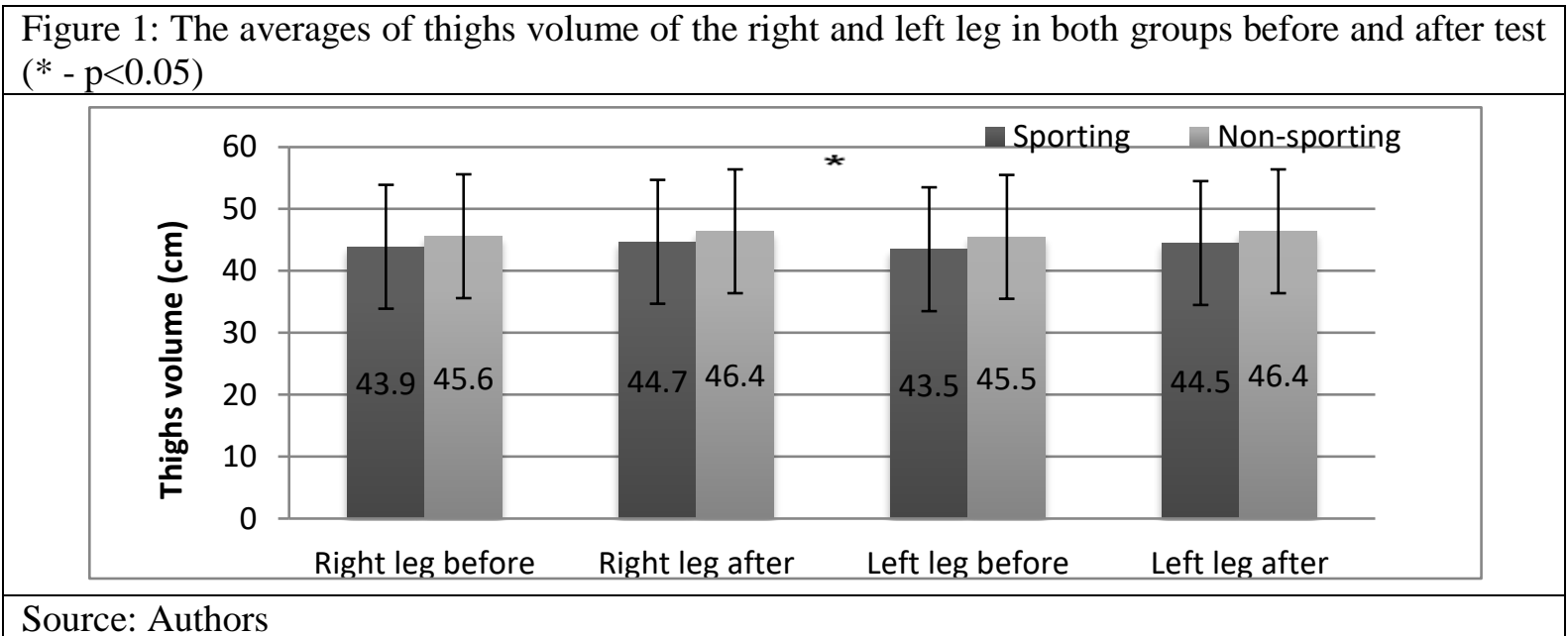

Comparing the results of quadriceps thigh muscle strength in separate groups (sporting and nonsporting) a statistically significant $(\mathrm{p}<0.05)$ increase is seen both in the right and left leg. Before and after testing, the quadriceps thigh muscle strength was statistically significantly $(\mathrm{p}<0.05)$ larger in both legs of sporting group compared to the non-sporting group.

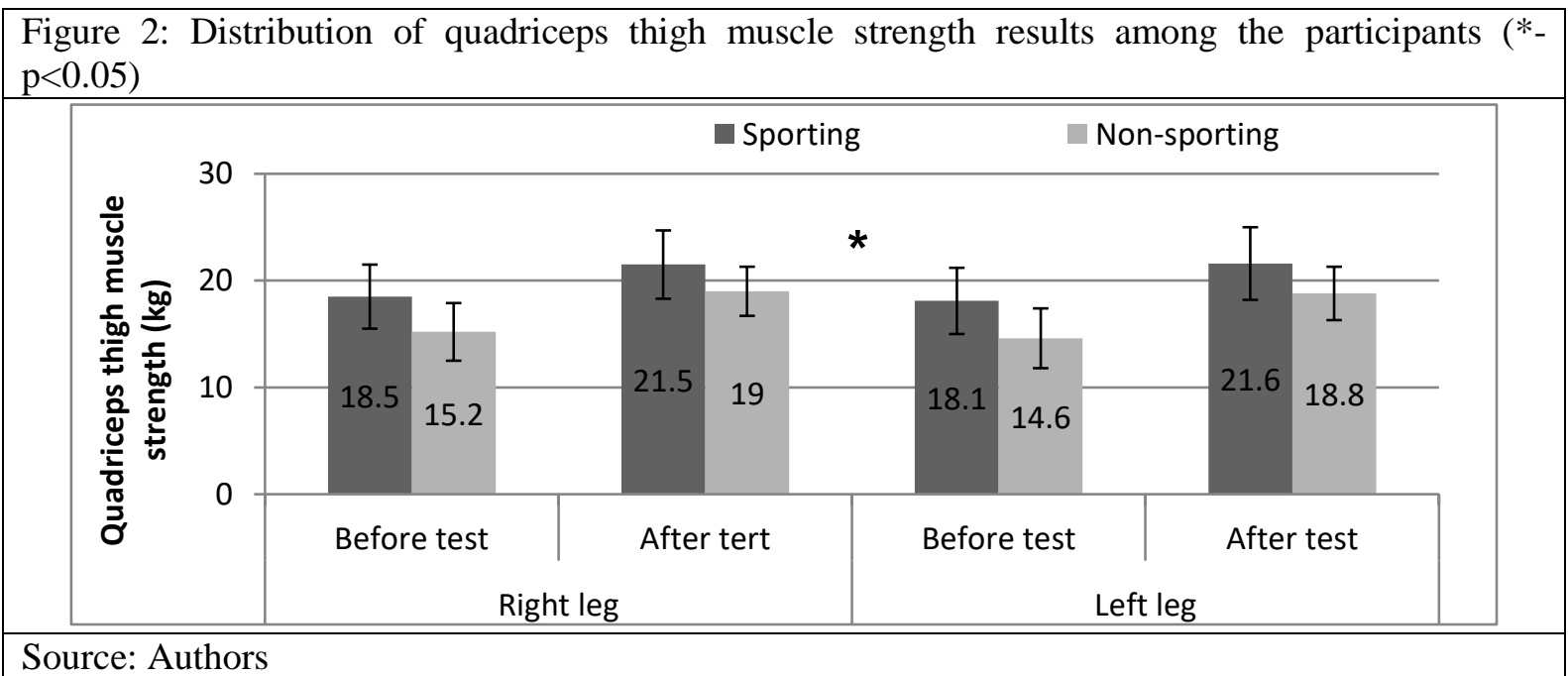


The applied strength training exercises mainly influenced muscle strength of the non-sporting group (muscle strength change in the right leg $-3.8 \pm 2.7 \mathrm{~kg}$, in the left leg $-4.2 \pm 3.0 \mathrm{~kg}$ ) compared to the sporting group (muscle strength change in the right leg $-3.0 \pm 2.1 \mathrm{~kg}$, in the left leg $-3.5 \pm 2.4 \mathrm{~kg}$ ) (Figure 2). As the non-sporting group was not trained, physical load affected their measuring results more. On the other hand, the sporting pupils were more adapted to physical load hence the applied load for them could be insufficient to obtain the results.

The results of quadriceps thigh muscle thickness in the right (Figure 3) and in the left leg (Figure 4) of both groups statistically significantly increased $(\mathrm{p}<0.05)$ in all measured points. Comparing the results between the groups before and after testing, the larger muscle thickness was measured in both legs of the sporting group, however, the statistically significant difference $(\mathrm{p}<0.05)$ was not obtained among all measurement points.

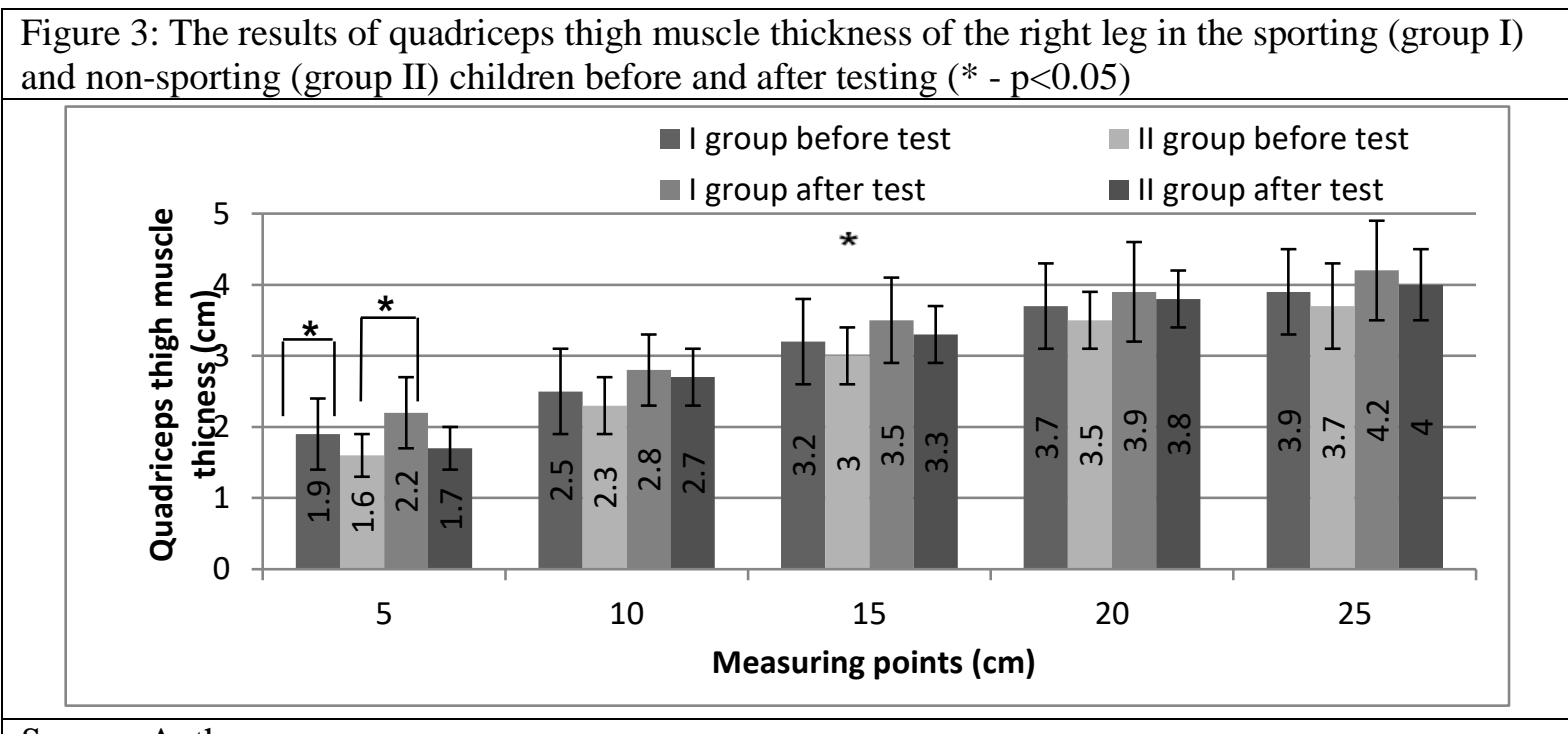

\section{Source: Authors}

Figure 4: The results of quadriceps thigh muscle thickness of the left leg in the sporting (group I) and non-sporting (group II) children before and after testing $(*-p<0.05)$

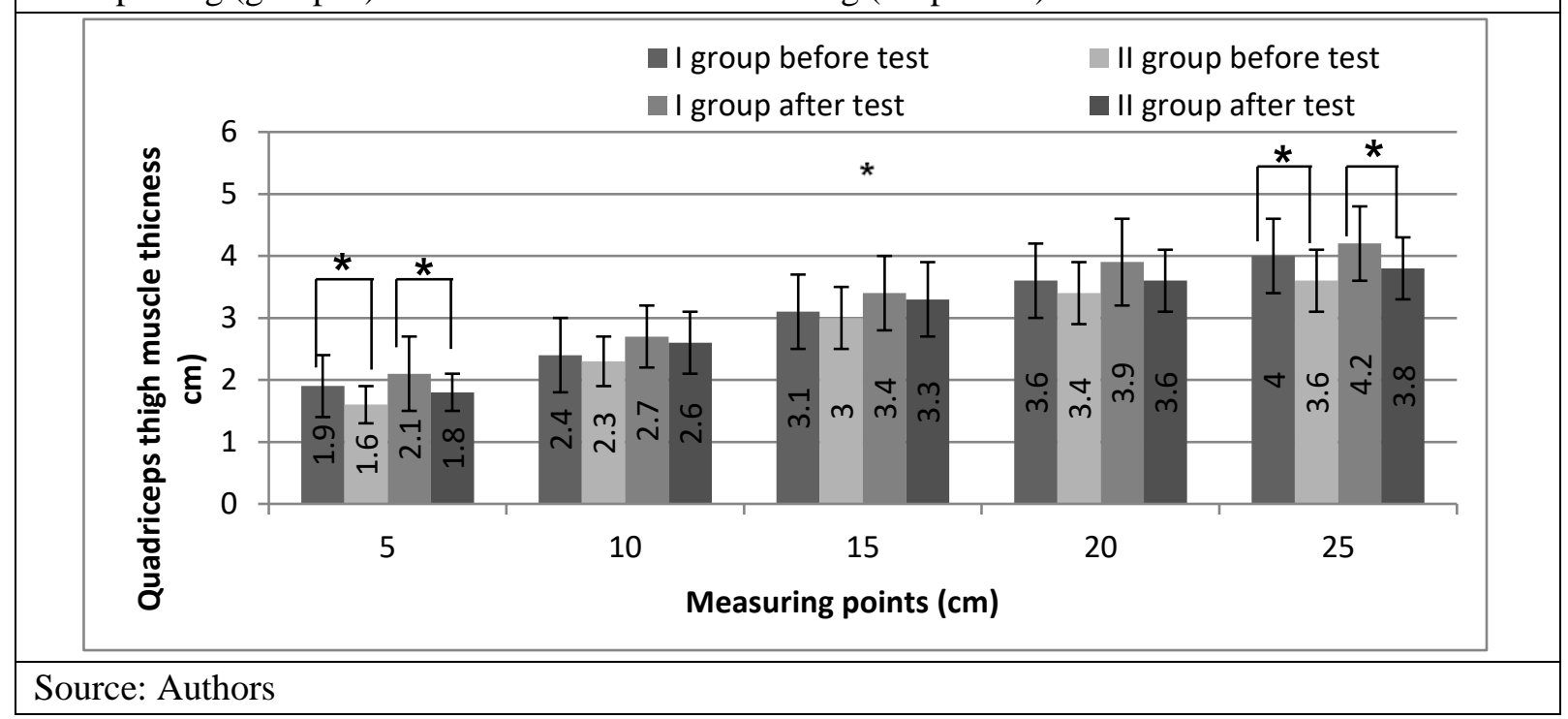

Assessment of the results of research in separate groups among sexes showed that for both girls and boys the thigh volume, muscle strength and quadriceps thigh muscle thickness (not in all points) increased statistically significantly $(\mathrm{p}<0.05)$. Statistically significant differences of the results among sexes were not noticed. The research data of the dominant and non-dominant leg showed that the results of all measurements in both groups statistically were not significantly different ( $p>0.05)$. 
Analysis of the correlation link between measured parameters showed that a stronger link was noticed in sporting group. In this group the statistically significant data $(\mathrm{p}<0.01)$ was obtained and the strongest link was received between quadriceps thigh muscle thickness and thigh volume (in the right leg: $r=0.9$ - before and $r=0.86$ - after, in the left : $r=0.74$ - before, $r=0.80$ - after). Less link was determined between quadriceps thigh muscle thickness and muscle strength (in the right: $\mathrm{r}=0.72-$ before, $r=0.71$ - after, in the left: $r=0.83$ - before, $r=0.73$ - after). The average strength link was received between muscle strength and thigh volume (in the right: $r=0.59$ - before, $r=0.64$ - after, in the left: $\mathrm{r}=0.63$ - before, $\mathrm{r}=0.58$ - after).

In the non-sporting group, the correlation links between the measured parameters were weaker than in sporting group, and most of the obtained data was statistically insignificant. In this group the positive correlation link was determined between thigh volume and quadriceps thigh muscle thickness (in the right: $r=0.6$ - before, after $-r=0.50$, in the left: before testing $r=0.63$, and after testing - strong link $\mathrm{r}=0.73$ ). The link between quadriceps thigh muscle strength and thickness was positive as well, (in the right: before -average correlation link ( $\mathrm{r}=0.66)$, after testing - strong $(\mathrm{r}=0.81)(\mathrm{p}<0.01)$; in the left: before - average link $(r=0.59)(p<0.05)$, after - the result became statistically insignificant $(p>0.01)$, and the link weak $-(\mathrm{r}=0.38))$. The weak link was received between thigh volume and quadriceps thigh muscle strength and had statistically insignificant results $(\mathrm{p}>0.01)$ and $(\mathrm{p}>0.05)$ (in the right: before $\mathrm{r}=0.11$, and after $-\mathrm{r}=0.39$, in the left: $\mathrm{r}=0.15$ - before, and after $-\mathrm{r}=0.19)$.

\section{Discussion}

Our research showed that the tested parameters (quadriceps thigh muscle thickness, strength and thigh volume) statistically increased significantly $(\mathrm{p}<0.05)$ after application of strengthening exercises. This conformed to other research works. Referring to the research performed by foreign authors during 4 weeks involving 5 times per week application of 2 different strengthening exercise programs, a statistically significant increase in quadriceps thigh muscle thickness and strength was received in both groups (Cho et al., 2018).

The performed research proved that muscle thickness as well as muscle strength increases by training. Since the muscle strength and muscle thickness were higher in the sporting group than in the nonsporting group, it can be stated that the results of the study coincided with the data of references and suggests that with increased muscle volume the muscle develops more force (Friesenbichler et al., 2018; McArdle et al., 2014).

It became clear that a better change in the results between measurements was received in the nonsporting group than in sporting group. Actually, this occurs because the sporting children are more trained and, therefore, due to applied exercises the indexes of measured parameters were less different. The rate of adaptation depends on training, hence less training means the greater indexes of adaptation. The sporting persons need physical loads of larger extent and intensity (Skurvydas, 2017).

The muscle strength of boys both before application of exercises and after it was larger compared to that of girls. We can state that the research data conformed with the statement of foreign authors, that boy participant muscle strength is 10 percent larger as their relative and absolute muscle mass is slightly larger than of girls. This difference becomes clear in the teenage years (Kisner \& Colby, 2017).

After the research it turned out that the results of the measured parameters between the dominant and non-dominant leg statistically were not significantly different $(\mathrm{p}>0.05)$. The research performed by McCreesh and Egan (2011) showed that the thickness of the front calf muscle group of the dominant leg was statistically significantly larger among football-players, but not among a control group (nonsporting persons) (McCreesh \& Egan, 2011). The results of the research performed by Legerlotz and colleagues (2010) were similar to our research data. The authors who studied the children's two-folded muscle architecture (muscle thickness, distribution corner of fiber and length of fibers) noticed that statistically there was significant difference between the left and right leg (Legerlotz et al., 2010).

It is known that isometric muscle strength depends on muscle thickness. Our results matched with the data of foreign authors that a strong correlation link exists between quadriceps isometric muscle strength and muscle thickness (Brody \& Hall, 2018; McArdle et al., 2014).

After analysis of the results, we may state that our hypothesis proved to be true and strengthening exercises had a positive effect on the increase of quadriceps thigh muscle thickness and volume. 


\section{Conclusion}

After application of strength exercises the increase in thigh volume, quadriceps muscle thickness and strength was statistically significant $(\mathrm{p}<0.05)$ in both groups: sporting and non-sporting. Quadriceps muscle thickness (high of $5 \mathrm{~cm})$ and muscle strength was statistically significantly greater $(\mathrm{p}<0.05)$ in the sporting group, and thigh volume increase was statistically insignificant greater $(p>0.05)$ in the non-sporting group.

Thigh volume between the genders in both groups did not show statistically significant difference $(p>0.05)$; muscle strength of boys was statistically significantly higher $(p<0.05)$ than girls; quadriceps muscle thickness was statistically significantly greater $(\mathrm{p}<0.05)$ in boys, but not in all measurement points.

Difference in thigh volume, quadriceps muscle thickness and strength between the dominant and nondominant leg was statistically insignificant $(\mathrm{p}>0.05)$ prior to and after the application of strength exercises.

The closest correlation was between the quadriceps muscle thickness and thigh volume as well as between the quadriceps muscle strength and thickness. The relation between the quadriceps muscle strength and thigh volume was average or weak.

\section{References}

Brody, L. T., Hall, C. M. (2018). Therapeutic exercise: moving toward function. Philadelphia: Wolters Kluwer. (Original work published 2002).

Cho, J., Lee, K., Kim, M., Hahn, J., Lee W. (2018). The effects of double oscillation exercise combined with elastic band exercise on scapular stabilizing muscle strength and thickness in healthy young individuals: a randomized controlled pilot trail. Journal of Sport Science \& Medicine, 17(1), 7-16.

Friesenbichler, B., Item-Glatthorn, J. F., Neunstöcklin, F., Casartelli, N. C., Guilhem, G., Maffiuletti, N. A. (2018). Differences in trunk and thigh muscle strength, endurance and thickness between elite sailors and non-sailors. Sport Biomechanics, 17(2), 216-226.

Kisner, C., Colby, L. A. (2017). Therapeutic exercise: faundations and techniques. Philadelphia: A. F. Davis Company. (Original work published 1985).

Legerlotz, K., Smith, H. K., Hing, W. A. (2010). Variation and reliability of ultrasonographic quantification of the architecture of the medial gastrocnemius muscle in young children. Scandinavian Society of Clinical Physiology and Nuclear Medicine, 3 (30), 198-205.

McArdle, W. D., Katch, F. J., Katch, V. L. (2014). Exercise physiology: energy, nutrition, and human performance. Philadelphia: Lippincott Williams and Wilkins. (Original work published 1981).

McCreesh, K., Egan, S. (2011). Ultrasound measurement of the size of the anterior tibial muscle group: the effect of exercise and leg dominance. Sports Medicine, Arthroscopy, Rehabilitation, Therapy\&Technology, 3(1):18. Retrieved from https://www.ncbi.nlm.nih.gov/pmc/articles/PMC3180254/

Radzevičienė, L., Vaitkevičius, J. V., Mockevičienė, D., Aleknavičūtè-Avlonskė, V., Dobrovolskytė, I., Miliūnienė, L., Navickienè, V., Savenkovienė A. (2016). Paauglių fizinis aktyvumas ir sveikata. Kaunas: Vitae Litera.

Reese, N. B. (2012). Muscle and sensory testing. St. Louis, MO: Elsevier Saunders. (Original work published 2002).

Regional Office for Europe of the World Health Organization (2017). Towards more physical activity: Transforming public spaces to promote physical activity - a key contributor to achieving the Sustainable Development Goals in Europe. Denmark: Copenhagen. Retrieved from http://www.euro.who.int/_data/assets/pdf_file/0018/353043/2017_WHO_Report_FINAL_WEB.pdf?ua=1

Skurvydas, A. (2017). Judesių mokslas: raumenys, valdymas, mokymas, metodologija, reabilitavimas, sveikatinimas, treniravimas. Kaunas: Vitae Litera. (Original work published 2008).

Skurvydas, A. (2011). Modernioji neuroreabilitacija: judesių valdymas ir proto treniruotė. Kaunas: Vitae Litera. 